Uşak Üniversitesi Sosyal Bilimler Dergisi

$2015,8 / 1$

\title{
Kadın ve Dil
}

Nazife AYDINOĞLU*

\begin{abstract}
Özet
Kültürün önemli öğelerinden olan dil, bir yandan toplumun gerçeklerini yansitırken, diğer yandan kültürün yeniden oluşumunu ve devamını sağlar. Bu nedenle ataerkil toplumlarda kadının ikincil konumda olmasının yansımalarını dil üzerinde izleyebildiğimiz gibi dilin toplumsal cinsiyet rollerini oluşturmadaki önemini görebiliriz. Toplumsal cinsiyet ve dil konusu, kadınların konuştuğu dil ve kadın hakkındaki dil olmak üzere iki farklı alanda incelenmelidir. Bu çalışmanın amacı iki konuya açıklık getirmektir. Bunlardan birincisi, Türkçede kadın hakkında kullanılan dilin onun ikincil konumuna ne derece 1şık tuttuğunu araştırmaktadır. Bu amaçla Metin Yurtbaşı'nın A Dictionary of Turkish Proverbs adlı sözlügüunün "Kadın" başlığı altında yer alan atasözleri incelenmiştir. İkinci amaç ise, kadının kullandığı dil ile onun konumu arasındaki ilişkilerini inceleyen araştırmaların tarihsel gelişimini örnek ve açılamalarla vermektir. Bu yapılırken üç ana dalga feminist hareketle görülen değişiklikler takip edilmiştir. Sonuç olarak Türkçede dil yoluyla kadının olumsuzlandığı ve aşağılandığı saptanmıştır. Toplumun gerçeklerini yansıttığı kadar bu gerçeklerin oluşumunu ve pekiştirilmesini sağlayan dilimizin bu ifadelerden arındırılmasıyla kadının konumunun iyileştirilebileceği konusuna dikkat çekilmek istenmiştir.
\end{abstract}

Anahtar Kelimeler: Toplumsal Cinsiyet, Dil, Türk Atasözleri.

\section{Women and Language: Portrayal of Women in Turkish Proverbs}

\section{Abstract}

Language is an important element of culture; it both reflects the realities of society and provides the reinforcement and re-establishment of it. This is why it is possible to trace how the secondary status of women is embedded in the language of patriarchal societies and to see its role on the formation of gender roles. Studies on gender and language should be carried out on two different areas: language about women and language women use. The aim of this descriptive study is to find out how Turkish language sheds light on the secondary status of women in Turkish society. To this

\footnotetext{
*Yrd. Doç. Dr., İzmir Üniversitesi Fen Edebiyat Fakültesi
} 
end, the proverbs under the title of "Women" are studied in Metin Yurtbaşı's dictionary titled A Dictionary of Turkish Proverbs. Another aim of the study is to give a historical survey of the studies in the field of the language women use. In this part, it is explained how these studies improved together with the three main waves of the feminist movement. As a result, it is found out that women in Turkey are given negative labels and scorned by means of the language. As languages reflect the realities of a society, strengthen them and form future of cultures, the necessity of eliminating these negative and belittling items in Turkish is highlighted.

Key Words: Gender, Language, Turkish Proverbs.

\section{Giriş}

Dünyanın birçok ülkesinde olduğu gibi 21. Yüzyıl Türkiye'sinde de alınan tüm tedbirlere ve yapılan tüm çalışmalara rağmen kadın ve erkek eşitliği henüz sağlanamamıştır. Bu bağlamda, kadına yönelik şiddet, kadınların aşağılanması, sosyal, politik ve iş yaşamlarında sürekli ikinci planda kalması, eğitim haklarından yararlanamaması toplumumuzda ivedilikle çözülmesi gereken önemli sorunlar arasında yer almaktadır.

Dil, toplumun bir yansıması, kültürün en önemli öğelerinden biridir. Kültürde var olan her gerçeğin göstergesi dil içinde bulunur. Bu nedenle toplum içerisinde kadın ve erkeğe farklı roller verilmesi, cinsiyetler arasındaki güç dengesizlikleri kadın ve erkeğin kullandıkları dili birbirinden farklılaştırmıştır. Aynı zamanda kadın ve erkekten bahsederken kullanılan dil arasında da farklılıklar vardır. Kadına yönelik şiddet çeşitlerinden biri olan psikolojik şiddette dil en etkin araç olarak kullanılır. Toplumsal cinsiyet ve dil arasındaki ilişkiler, 1970'li yıllardan itibaren dil çalışmalarına feminist açıdan bakan dilbilimcilerin dikkatini çekmiştir. Bu konuda ilk çalışanlardan biri olan Robin Lakoff'tan bu yana alanda çalışmalar büyük bir çeşitlilik göstermektedir.

Kadın ve dil konusu ele alındığında iki alan söz konusudur. Bunlardan ilki kadın hakkında kullanılan dil, başka bir deyişle kadını tanımlarken ve betimlerken kullanılan dil; ikincisi de kadının konuşurken kullandığı dildir. Gerek kadın hakkında kullanılan dil, gerekse kadının kullandığı dil kadının toplum içindeki konumunu, kadına karşı takınılan tutumu, kadına verilen değeri ya da değersizliği açıkça göstermektedir. Bu çalışmanın amacı, kadın ve dil konusuna kısa bir kuramsal giriş yaptıktan sonra, Metin Yurtbaşı'nın "A Dictionary of Turkish Proverbs" adlı kitabında "Kadın" başlığı altında yer alan atasözlerinden yola çıkarak Türkçedeki 
kadın hakkındaki dilin Türk kültüründeki kadın kimliğini yansıtmada ve oluşturmadaki etkilerini ortaya koymaktır.

\section{Kadın Hakkında Dil}

Kadın hakkındaki dile "kadın" sözcügünün kullanımı ve çağrışımları ile başlamak gerekir. Bir dilde "kimi varlıklardan, nesnelerden söz edildiğinde doğacak korku, ürkme, iğrenme gibi duyguların, kötü izlenim ve çağrışımların önlenmesi amacına yönelen ve dünyanın her dilinde rastlanan değiştirme olayı"na (Aksan, 1998: 98) örtmece, güzel adlandırma denir. Türkçede saygı duyduğumuz kadınlardan bahsederken veya onlara hitap ederken "kadın" kelimesinden kaçınılır, yerine "bayan" kelimesi kullanılmaya çalışılır. Bu örtmece, kadın kelimesinin kimi durumlarda kötü izlenim ve çağrışımlar yaptığının bir göstergesidir. Nedir kadın kelimesini bu kadar ürkütücü, korkutucu, iğrendirici yapan? Kadının aşağılık ve tehlikeli bir varlık olması mı? Bir cinsel nesne olarak görülmesi mi? Yoksa kadınların saygınlığının bulunmaması mı? Son iki seçenek daha akla yakın geliyor. Lakoff, İngilizcede de var olan bu kadın/ bayan (woman/lady) örtmecesinden bahsederken "kadınlara daha fazla saygı duymaya ve onlardan ve onların toplumda var olan, erkeklere ilişkin rollerinden daha az rahatsız olmaya başlayıncaya kadar" kadın sözcüğü bizi rahatsız etmeye devam edecektir, der (Lakoff,1973: 58).

Gerek Türkçede gerekse İngilizcede kadınların iş yaşantısında yerlerinin olmadığı "işadamı" sözcüğünde açıkça belirgindir. Son yıllarda bunu değiştirmek için "işkadını" sözcüğü kullanılmaya başlansa da birçok yerde işadamı karşımıza çıkmaktadır. Bu durum bazen garip olaylara da neden olmaktadır. 2013 yılında 8 Mart Dünya Kadınlar günü kapsamında İzmir Üniversitesi'ne bir konferans için gelen EGİAD (Ege İşadamları Derneği) başkanı Seda Kaya isimli bir bayan olması bu duruma ilişkin çarpıcı bir örnektir. Aynı şekilde Türk üniversitelerinde hemen hemen erkek sayısına eşit kadın bilim adamı(!) vardır.

Bazı mesleklerin erkeklere bazılarının kadınlara atfedilmesinden dolayı, Türkçede "kadın doktor", "kadın avukat", "kadın mühendis", "kadın subay", "kadın pilot", "kadın şoför" gibi ifadeler kullanılmaktadır. Aynı şekilde son zamanlarda erkeklerin de hemşirelik mesleğine girmeleri ile "erkek hemşire" sözcüğü kullanılmaya başlanmıştır.

Dilimizdeki birçok ifade, kültürümüzde kadının konumunun ve değerinin erkeğin konumu ve değerinden düşük olduğunu somut bir şekilde göstermektedir. "Adam olmak", "bir işi adam gibi yapmak", "erkek adammış", "erkek kadınmış", "adam gibi adam", "karı kılıklı", "karı gibi gülme", "kız kurusu", "evde kalmış kız" gibi deyimler, erkek olmanın 
yüceliğini ve erdemini, erkeğin yaptığı işlerdeki becerisini ve başarısını, erkeğin değerini yaşla yitirmediğini vurgularken kadını olumsuz ve ikincil duruma konumlamaktadır.

\section{Kadının Kullandığı Dil}

Kadının kullandığı dil üzerindeki çalışmalar sırasıyla dört ayrı görüşü ortaya çıkarmıştır. Bunlardan sadece biri feminist hareket öncesine, üçü ise üç ayrı feminist dalga ile paralel zamana denk gelir. Bu görüşler kısaca şöyle açıklanabilir:

1- Kadının kullandığı dil erkeğin kullandığı dilden daha kötüdür.

2- Kadının kullandığı dil erkeğin kullandığı dilden farklıdır çünkü onun toplumdaki ikincil konumunu yansitır.

3- Kadının kullandığı dil erkeğin kullandığı dilden farklıdır, çünkü kadının dili kullanma amacı farklıdır.

4- Kadının kullandığı dil onun kimliğini oluşturur.

1- Kadın dili konusuna ilk değinenlerden biri olan Otto Jesperson, kadın dilinin birçok eksikliği ve hatasının bulunduğunu çünkü kadınların düşünmeden konuştuklarını iddia eder. Dil: Özellikleri, Gelişimi ve Başlangıcı (Language: Its Nature, Development and Origin)(1992) adlı eserinde kadın dilinin zayıflıklarını şöyle açıklar:

- Kadınların sözcük hazinesi daha dardır;

- Kadınlar konuşmalarında gereksiz sıfatlar kullanırlar;

- Cümleleri yarım bırakırlar;

- Abartılı konuşurlar;

- Kaba sözcükler ve küfür kullanmaktan kaçınırlar;

- Dolayli ifadeyi tercih ederler;

- Cümlelerini sık sık "ve" sözcügü ile birbirine bağlarlar

- Daha az sözcük kullanmalarına karşın daha akıcı konuşurlar.

2- Kadın ve dil konusu Feminist hareketin başlamasıyla birlikte tekrar gündeme gelmiş ve bu konuda yaygın olarak çalışmalar yapılmaya başlanmıştır. Bu dönemde yapılan ilk çalışmaların özünde, "Kadının kullandığı dil erkeğin kullandığı dilden farklıdır çünkü kadının konumu daha düşüktür; erkek dilde de hakimiyetini gösterir" düşüncesi vardır (Jespersen 1922; Lakoff 1973, 1975; Zimmerman \& West 1975; Fishman 1978; O’Barr \& Atkins 1980; Spender 1980; Greif 1980; Beattie 1981; Coates 1986).

Kadın ve dil konusunu ciddi olarak ilk ele olan ve bu konuda ilk yayınları yapan, California Üniversitesi Dilbilim profesörlerinden Robin Lakoff'dur. Lakoff, Language and Woman's Place (1973) makalesinde ve daha sonra aynı başlıklı kitabında kadının güçsüzlüğünün ve toplumdaki ikincil konumunun hem onun konuşması beklenilen dilde, hem de onun 
hakkındaki dilde görüldüğünü öne sürer. Ona göre hanım hanımck davranması beklenen kadının hanım hanımcık konuşması duygularını ve düşüncelerini açıkça ve kuvvetli bir şekilde ifade etmesini, erkek dünyasının önemli konularını dile getirmesini engeller. Lakoff, aynı eserinde kadın dilinin ortak özelliklerini ve erkek dilinden farklılıklarını verir. Bu özellikler kısaca şöyle sıralanabilir:

- Kadın dili oldukça kibardır; "Bir mahzuru yoksa”, “... Yaparsan çok memnun olurum" gibi ifadeler sıklıkla kullanırlar;

- Özür diler gibi bir tonla konuşurlar;

- Düz cümleleri bile soru sorma tonlamasıly söylerler;

- Düzgün bir dilbilgisi kullanmaya özen gösterirler;

- Düşündüklerini doğrudan ifade etmeye çekinirler. "sanırım", "öyle olduğunu düşünüyorum" gibi ifadeleri sıklıkla kullanırlar;

- "Değil mi?" ekini çok sık kullanırlar;

- Daha alçak sesle konuşurlar;

- Daha çok soru sorarlar;

- Daha çok özür dilerler;

- Beğenilerini göstermek için kullandıkları sözcükler daha abartılıdır;

- Kadınlar bir konudan rahatsız olduklarında mızmızlanır, şikâyet ederler, fakat erkekler avaz avaz bağırır;

- Bir şeye sinirlendiklerinde kullandıkları ünlemler farklıdır. Kadınlar "Aman Allahım", "Ya Rabbi" gibi sözcükler kullanırken erkekler "Allah kahretsin" gibi sözcükler kullanır.

- Küfür sözcükleri kullanmaktan kaçınırlar;

- Renkler konusunda kendilerine özgün zengin bir sözcük dağarcıkları vardır;

- Konuşurken bazı sözcükleri vurgularlar;

- Fikra anlatamazlar.

Lakoff'un listesinde verilen kadın dilinin özellikleri onlara yüklenen toplumsal cinsiyet rolleri ile örtüşmektedir. Kadınların kullandığı dil ile verdikleri izlenim, kibar, kendi küçük dünyaları dışında kalan konularda net fikirleri olmayan, güvensiz olduklarından sürekli onaylanma gereksinimi hisseden, karşısındaki ile çatışmaya girmekten çekinen, sesleri fazla duyulmayan, sık hata yapıp özür dileyen, kendilerini dolaysız ifade edemeyen kişiler olduklarıdır. Bunun sonucunda gerek aile içinde gerekse sosyal yaşamda ve iş yaşamında ciddiye alınmazlar.

William O'Barr ve Brown Atkins 1980 yılında yaptıkları bir çalışmada mahkeme salonlarında yargılanan kişilerin ses kayıtlarını incelemişler ve Lakoff'un kadınlara atfettikleri dil özelliklerinin güçsüz kişilerin dil özellikleri ile örtüştüğünü iddia etmişlerdir. Her iki çalışmanın 
sonucu, toplumdaki hiyerarşik yapı ve güç ilişkilerinin kullanılan dil ile doğrudan ilişkili olduğunu göstermektedir.

Konuyla ilgili yapılan diğer çalışmalarda Zimmerman ve West (1975), kadınların erkeklerle yaptığı konuşmalarda erkeklerin kadınların sözünü daha sık kestiklerini gösterir. Esther Grief 1980 yılında yaptığı çalışmada, anne ve babaların kız çocuklarının sözünü erkek çocuklarından daha fazla kestiklerini ve babaların annelerden daha fazla çocukların sözünü kestiklerini bulmuştur. Pamela Fish (1983), kadın erkek arasındaki konuşmaların başarısızlığının nedenini kadının konuşmasındaki özelliklere değil, erkeğin konuşmayı sürdürmek için geri dönütü sağlamamasına ve yanıt vermemesine bağlar; kadınların konuşmayı dinlerken ilgilendiklerini sözler ve mimiklerle açıcça gösterdiğini ve böylece konuşmacıyı desteklediğini belirtir. Jennifer Coates ise yaptığı araştırmada, kadınların erkeklerin açtı̆̆1 konularda konuştuğunu fakat erkeklerin kadınların başlattığı konularda konuşmak istemediklerini gösterir (1986).

3- Kadın ve dil çalışmalarındaki ikinci görüş, kadının kullandığ dilin erkeğin kullandığı dilden zayıf olmadığı ama farklı olduğudur. İkinci dalga feministler, erkeklerin egemen olduğu bir dünyada normların erkekler tarafından belirlendiğini, kadınların bu normlara göre değerlendirildikleri için farklılıklarının her zaman bir küçüklük, bir eksiklik gibi algılandığını öne sürmüşlerdir. Erkeklerden farklı olmaları onların daha güçsüz, daha akılsız, daha yeteneksiz olduğunu göstermez. Kadın dilini bu bağlamda inceleyen araştırmacılar kadın dilinin erkek dilinden farklı olmasını kadınların dili farklı amaçlarla kullanmalarına bağlamışlardır (Coates 1986, Coates \& Cameron 1988, Tannen 1990, Gray 2012).

Deborah Tannen, Sen Beni Anlamiyorsun (You just Don't Understand) (1990) adlı kitabında bu farklılıkları şöyle özetler:

- Erkek için dil bir statü gösterme, gücünü ortaya koyma aracıdır, kadın ise dili ilişkilerini sağlamlaştırmak, yakınlığı artırmak için kullanır. Erkekler dünyayı hiyerarşik bir ortam olarak görür, kadınlar ise eşit ilişkiler ortamı olarak görürler. Kadınlar için dostluk ve paylaşım; erkek için güç önemlidir.

- Gücün ve statünün önemli olduğu bir dünyada bağımsız olmak çok önemlidir; ilişkilerin önemli olduğu bir dünyada ise yakınlık kurmak önemlidir.

- Kadınlar bir karara varmadan önce bunu yanındakilerle konuşmak, onların fikrini sormak, düşüncelerini paylaşmak ister. Erkekler ise bundan sıkılır, kendi başlarına karar vermekten hoşlanırlar.

- Bir erkek için bir sorundan bahsetmek ona bir çözüm bulunmasını istemektir; bu nedenle hemen tavsiyede bulunmaya başlar. Kadın 
için ise bir sorundan bahsetmek anlaşılmak istemektir; bu nedenle çözüm önerisinde bulunulmasını beklemez. O hissettiklerini paylaşmak ister.

- Kadınlar bilgi alıp vermek için konuşur; kadınlar ise duygularını ifade etmek için konuşur.

- Erkekler bir şey yapılmasını istediklerinde emir verirler, kadınlar ise öneride bulunurlar.

- Erkek dünyası yarışma ve çatışma dünyasıdır; kadın dünyası ise uzlaşma ve barış ister.

- Kadınlar pozitif duyguları ifade etmede daha iyidir, erkekler ise kızgınlıklarını daha iyi ifade ederler.

4- Kadın ve dil konusundaki üçüncü görüş ise üçüncü dalga feminizme paralel postmodern bir yaklaşım olan sosyal yapılandırmacılıktır. Bu görüş kadının kullandığı dilin onun kimliğini oluşturmada önemli bir rol oynadığını iddia eder. Daha önceki iki görüşü eleştirir çünkü önceki iki model de kadın erkek dili arasındaki benzerlikleri, kadınların ve erkeklerin kendi dilleri içindeki farklılıkları ve dilin konuşulduğu ortamı göz ardı etmektedir. Bu yeni yaklaşım ile kadın dili çalışmaları tümce düzeyinden söylem düzeyine taşınmış ve dil sayesinde toplumsal cinsiyetin nasıl oluşturulduğu tartışılmaya başlanmıştır (Cameron, 1990, 1995).

Cinsiyet biyolojik, toplumsal cinsiyet ise sosyal bir olgudur ve davranışlarla, söylemle şekillendirilir. "Erillik" ve "dişilik" doğuştan gelmez, içinde yaşanılan kültürel normlara göre yapılan etkinliklerle toplumsal olarak oluşturulur (Butler 1993, Goodwin 1998). Kimliğimizin bir parçası olan toplumsal cinsiyet, tek ve durağan değil, çoklu ve değişkendir, sürekli olarak yeniden yapılanır. Kadın ve erkek aynı kültürün ayrı birer parçası olarak yetiştirildiklerinden farklı alt kültürler oluştururlar. $\mathrm{Bu}$ nedenle kadın-erkek iletişimi kültürlerarası iletişim gibidir.

Dil sosyal bir yapı, dil kullanımı sosyal bir etkinliktir. Dil sayesinde bir yandan sosyal dünyayı anlarken diğer yandan bu dünyayı şekillendiririz (Freeman\& McElhinny 1996). Dil, toplumsal cinsiyetin oluşturulmasında kullanılan en önemli etkenlerden biridir; toplumsal cinsiyet yazılı ve sözel dilde yapılanır ve ortaya konur. Bu nedenle cinsiyetin dil içinde nasıl yansıtıldığına bakmak yerine, söylem içinde nasıl oluşturulduğuna bakmak daha yerinde olur (Eckert \& McConnell 1992).

Jane Sunderland, toplumsal öğrenme kavramını toplumsal oluşturma kavramı ile değiştirmektedir çünkü toplumlar kendi dinamikleri içinde her türlü sosyal davranışları ile kültürlerini oluştururlar (2004). Dilin kimlikleri oluşturmak için kullanıldığı en önemli kurumlardan birinin okullar olduğuna inanan Sunderland, İngilizce ders kitaplarında toplumsal 
cinsiyet rollerini incelemiş, bu kitaplarda kadın karakterlerin sayısının daha az olduğunu, kadın-erkek meslek ayrımı yapıldığını, kadınların korkak ve duygusal olarak gösterildiklerini, kadınlara daha az söz verildiğini ve kadınlar hakkında aşağılayıcı ifadeler bulunduğunu saptamıştır (1996).

\section{Türk Atasözlerinde Kadın}

İster yansıtmacı yaklaşımlarla isterse yapılandırmacı yaklaşımlarla bakılsın dil ve toplumsal cinsiyet arasında karşılıklı bir etkileşim olduğu aşikârdır. Çalışmanın bu bölümünde Türk atasözlerinde kadının toplumdaki konumu ve bu atasözlerinin kullanımı ile kadının toplumsal cinsiyetinin nasıl oluşturulduğu ve pekiştirildiği incelenecektir. Çalışmada, Metin Yurtbaşı'nın A Dictionary of Turkish Proverbs (türkçe ad) adlı kitabının "Kadın" başlığı altında bulunan 72 atasözü örneklem olarak alınmıştır. Atasözleri olumlu, olumsuz ve yansız olarak sınıflandığında, 46 olumsuz, 9 olumlu, 17 yansız atasözü bulunmuştur. İlk gruptaki 46 atasözü, olumsuz çağrışımları ile birlikte aşağıda verilmiştir (Yurtbaşı 2012: 424-429):

1- Kadınlar güvenilmezdir:

Örnek 1: Ak akçe ile ak baldıra güven olmaz.

Örnek 2: At ile avrada inan olmaz.

Örnek 3: Kadın deniz gibidir.

Örnek 4: Kadına, çocuğa, sarhoşa sırrını açma.

2- Kadınlar sır tutamazlar:

Örnek: Arı sırrı, karı sırrı.

3- Kadın kötü ve tehlikelidir:

Örnek 1: Ateşle oynama, elini yakar; avratla oynama, evini yakar.

Örnek 2: Kadın şerri, şeytanın şerrine eşittir.

Örnek 3: Kadının şerri şeytan şerrinden eşettir.

Örnek 4: Kadının şerrinden Allah'a sığınmalı.

4- Kadın sözü dinlenmemelidir:

Örnek 1: Avradın övüdü avrada geçer.

Örnek 2: Karı sözüne uyan adam değildir.

Örnek 3: Karıya bakanın aklı az olur.

Örnek 4: Kırk yılda bir karı sözü dinlenmelidir.

5- Kadın ikiyüzlüdür:

Örnek: Avrad gibi düşman olmaz, güler bildirmez, köpek gibi dost olmaz, ulur bildirmez.

6- Kadın halden anlamaz:

Örnek: Avrat kıtlık bilmez, çoban yokluk bilmez.

7- Kadın vefasızdır:

Örnek: Avrattan vefa, zehirden şifa. 
8- Kadın kavgaya neden olur, bela getirir:

Örnek 1: Bal arıdan, kavga karıdan çıkar.

Örnek 2: Güzel nerde kavga orda.

9- Kadınlar erkek dünyasından ve erkek işlerinden uzak

durmalıdır:

Örnek: Elinin hamuruyla / Elindeki hamura bakmaz erkek işine karışır.

10- Namus kadın için çok önemlidir:

Örnek: Erkeğin eli kınası, kadının yüzü karası.

11- Kadınlar açgözlüdür:

Örnek: Erkeğin nefsi birdir, kadının ki dokuz.

12- Kadın şeytandır:

Örnek 1: Erkeğin şeytanı kadındır.

Örnek 2: Kadın erkeğin şeytanıdır.

13- Kadınlar eğlenceye düşkündür:

Örnek: “Gökyüzünde düğün var” deseler, kadınlar merdiven

kurmaya kalkar.

14- Kadın satılacak maldır:

Örnek: Hayvanın erkeğine para verirler, insanın dişisine.

15- Kadın erkeğe bağımlıdır:

Örnek 1:Horozsuz tavuk, çobansız sürüye benzer.

Örnek 2: Horozsuz tavuk yaşayamaz.

16- Kadınlar akıllı değildir:

Örnek 1: Kadın aklı gâh uzalır, gâh kısalır.

Örnek 2: Kadın kısmının saçı uzun olur, aklı kısa.

Örnek 3: Karının bir aklı, erkeğin dokuz aklı.

17- Kadın değersizdir:

Örnek: Kadın erkeğin elinin kiri.

18- Kadınların acı çekmesi kaçınılmazdır:

Örnek: Kadın kısmı kara yazılıdır.

19- Kadının malından hayır gelmez:

Örnek 1: Kadın malı hamam tokmağı.

Örnek 2: Kadının malı kapı mandalı.

20- Kadın kurnazdır, dikkat et:

Örnek 1: Kadın şeytana pabucunu ters giydirir.

Örnek 2: Kadının fendi erkeği yendi.

21- Kadın huysuzdur:

Örnek: Kadına söz duyurabilmek için güleç zamanını

beklememeli.

22- Kadın tüketicidir: 
Örnek: Kadının gırtlağı olmaz.

23- Kadının yaptığ 1 işten hayır gelmez:

Örnek 1: Kadının kazdığı kuyudan su çıkmaz.

Örnek 2: Kadının yüklediği yük şuradan şuraya varmaz.

Örnek 3: Karıdan hayır gelmez.

Örnek 4: Kadınların işi tavuk eşinmesine benzer.

24- Kadından sofu olmaz.

Örnek: Kadının sofusu şeytanın maskarasıdır.

25- Kadınlar gevezedir:

Örnek: Kadının zoru diline kuvvet.

26- Kadınlar güçsüz ve kırılgandır:

Örnek: Kadınlar eğe kemiğinden yapılmıştır.

27- Kadınla yola çıkılmaz, iş yapılmaz:

Örnek: Karı ile çıkma yola, başına gelir türlü bela.

Kadını yeren, küçümseyen 46 atasözünün konu ettiği 27 ayrı özelliğin hepsi hakkında araştırma yapıp bu çalışmaya dâhil etmek olası değildir ama kadın ve dil konusunu ilgilendirdiği için biri hakkında birkaç uzman görüşü yazılabilir. Hemen hemen her dilde kadınların geveze olduklarına dair atasözleri ve deyimler bulunur. Ama yapılan çalışmalar kadınların erkeklerden daha çok konuştuğunu kanıtlar nitelikte değildir. Dale Spencer, "Kadınların konuşmaları erkeklerin konuşmasıyla değil, sessizlikle karşılaştırılıp değerlendirildiğinden kadının söylediği her söz çok fazla görülebilir." diyerek toplumda kadına söz hakkı verilmediğini ifade etmiştir (1980: 42). Deborah Tannen, konuya başka bir açıdan bakarak kadının ve erkeğin konuştuğu yerlerin farklı olduğuna değinir. Kadının konuştuğu mekânlar genellikle evi ve özel mekânlar iken erkekler toplum içerisinde ve dış mekânlarda daha konuşkan olurlar (1990: 78, 87).

İncelenen 72 atasözünden sadece 9'unda olumlama vardır. Bunlardan dördü kadının eş ve annelik rollerine ilişkindir (Örnek 2, 4, 8, 9). Zaten Türk toplumunda kadın olarak aşağılanan dişi, anne olarak kutsanır; evine baktığı, çocuklarını yetiştirdiği ve eşine destek olduğu için kadın eş ve anne olarak değerlidir. Bu nedenle kadınlara sosyal yaşamda ve iş yaşamında yer edinmeye çalışmaktansa kendilerine biçilmiş mekân olan evlerinde kalmak öğretilir. Atasözlerinden biri kadının merhametli olduğunu belirtirken (Örnek 6), bir diğeri kadının namusunu korumak için bir erkeğe gereksinim duymayacağını vurgular (Örnek 5). Atasözlerinden yalnızca biri kadınla erkeğin insan olarak aynı yapıya sahip olduğuna dikkat çeker (Örnek 3). Bir diğerinde ise kadının hünerli olduğu, on parmağında on marifet bulunduğu abartı kullanılarak "kırk çırağı" ile anlatılır (Örnek 7).

Örnek 1: At ile avradın yediği sayılmaz. 
Örnek 2: Beşiği sallayan el dünyaya hükmeder.

Örnek 3: Erkek aslan aslan da, dişi aslan aslan değil mi?

Örnek 4: Erkek aslan dişisine bakar da kuvvet alır.

Örnek 5: Kadını erkek değil, ar ve namus korur.

Örnek 6: Kadının kalbi merhamet kaynağıdır.

Örnek 7: Kadının kırk çırağı var biri sönse biri yanar.

Örnek 8: Kadınsız ev olmaz.

Örnek 9: Yuvayı yapan dişi kuştur.

Kadına olumlayan grubunda ele aldığımız atasözlerinde bile alt anlamlara ve sözcük seçimlerine bakıldığında bir olumsuzlama yakalanabilir. Örneğin, "At ile avradın yediği sayılmaz" atasözünde at ile kadının yediğinin karşılığını verdiği ve çok çalıştı̆̆ 1 vurgulanırken, satır arasında kadına "Sen tüketicisin, bu yüzden yediğinin laf edilmemesi için evde çok çalışıp bunun karşılığını vermelisin" mesajı verilmektedir. Kadının merhametli ve namuslu olmasının övüldüğü atasözlerine bir başka açıdan bakıldığında, bu iki atasözünün (hangileri) kadının toplumca onaylanan özelliklerini öne çıkardığı, toplumda kabul görmek isteyen kadınların bu konulara özen göstermeye yöneltildiği söylenebilir. Aynı zamanda bu özelliklerin erkeklerden beklenmemesi gerektiği de çıkarılabilir.

Atasözlerinin bazılarını kadını olumlayan ya da olumsuzlaştıran gruplara sokamayız. Bunları yansız veya tarafsız diyebileceğimiz üçüncü bir gruba sokmak gerekir. 72 atasözünden 17'si bu grupta toplanmıştır.

Örnek 1: Aslan bile kadına dokunmaz.

Örnek 2: Avrat, at, bağ sahibini hep genç ister.

Örnek 3: Kadınla tavuk bağlanmaz.

Örnek 4: Avrat vardır, arpadan aş eder, avrad vardır, bulguru keş eder.

Örnek 5: Bağın taşlısı, karının saçlısı.

Örnek 6: Beyazın adı var, esmerin tadı.

Örnek 7: Kadın var kardan soğuk, kadın var kordan sıcak.

Örnek 8: Çirkin karı evin toplar, güzel karı düğün/sokak gezer.

Örnek 9: Er kemaliyle, erkek cemaliyle anılır.

Örnek 10: Er kocarsa/kocadıkça, koç olur; karı kocarsa/kocadıkça

hiç olur.

Örnek 11: Erkeğin iyisi eşeğinden, kadının iyisi eşiğinden bellidir.

Örnek 12: Kadın kadıncık gerek.

Örnek 13: Kadını evinden erkeği pirinden sorarlar.

Örnek 14: Kadını hamarat eden ateştir.

Örnek 15: Kadının temizi sırtından, sütün temizi yoğurdundan bellidir. 
Örnek 16: Kadınlar kurnaz oldu, bazlamacı küçük küçük tutar; çocuklar da hokkabaz oldu bazlamacı çift çift kapar.

Örnek 17: Karın soğuğu, karının soğuğundan iyidir.

Tarafsız gruba koyduğumuz atasözlerine baktığımızda aslında bunların içinde de gizli bir olumsuzluluk bulunduğunu fark ederiz. "Aslan bile kadına dokunmaz" atasözünde, kadına yönelik vahşetin yaygın olduğu ve bunu durdurmak için aslan gibi vahşi bir hayvanın bile kadına zarar vermeyeceği vurgulanmaktadır. Aynı atasözü içinde erkeğin açıkça bir yüceltilmesi de vardır.

Erkekler çağrışımları kuvvet, iktidar, güç ve yenilmezlik olan aslanla özdeşleştirilirken, kadınlar daha zayıf ve edilgen hayvanlarla temsil edilirler. Kadının özgürlüğüne düşkün olduğunu, onu çok fazla sıkmamak gerektiğini belirten "Kadınla tavuk bağlanmaz" örneğinde, kadınla eşleştirilen "tavuk" tur (Örnek 3). Çağrışımlarına bakıldı̆̆ında tavuk, kendisinden her türlü yararlanılan ama uysal, aptal olduğuna inanılan bir hayvandır. Erkeğin özgürlüğe düşkünlüğü betimlenirken kullanılan benzetme genellikle kartal ve aslan gibi çağrışımları yüceltici olan hayvanlar iken, kadın için tavuk uygun görülmektedir.

Tarafsız gruptaki atasözlerinin bir kısmı kadını bir meta olarak değerlendirir ve onun dış görünüşüne gönderme yapar. Kadının değeri onun güzelliği, erkeği cezbetmesi ve hoşnut edebilmesiyle orantılıdır (Örnek $5,6,8)$. Güzel olan kadın vücuduyla değer kazandığından ev işleri yaparak kendini kabul ettirmek zorunda değildir. Yaşlanmak kadın için "hiç" olmak demektir, çünkü güzelliğini kaybeder; erkeğin ise böyle bir tasası yoktur; kadının aleyhine olan yıllar erkeğin lehine işler; o yaşlandıkça kıymetlenir, bir "koç" olur.

Yansız olarak grupladığımız atasözlerinin bazıları toplumsal cinsiyet rollerini vurgular niteliktedir. Bunların bir kısmı kadının evini temiz tutmak, yemek yapmak görevlerini vurgularken (Örnek 4, 11, 13, 14, 15), bir kısmı da kadının cinsel çekiciliğinin ve sıcaklığının önemine değinmektedir (Örnek 7, 17). Kadının cinsiyete bağlı kişiliği ve rolü olmalıdır. Kız çocuklarının doğduğu günden itibaren hanım hanımcık davranmaları ve konuşmaları beklenir. Kız çocukları yüksek sesle konuşmaz, küfretmez, kibar olmalıdırlar. Örnek 10, bunu "Kadın kadıncık gerek" diyerek öz bir şekilde ifade eder.

Çalışmanın başında, ataerkil bir yapıya sahip olan Türk toplumundaki atasözlerinde kadının ikincil konumda görüleceği ve aşağılayıcı ifadeler kullanılacağı öngörülmüş, yapılan incelemeler bu öngörüleri doğrulamıştır. Kadın başlığı altında yer alan 72 atasözünün 45'inde olumsuz, sadece 9'unda olumlu anlam olduğu saptanmıştır. 
Atasözlerinden 17'si yansız olarak belirtilse de bunların derin anlamlarının olumsuzluk yüklü olduğu fark edilmiştir.

Jane Sunderland'ın Language and Gender (2006) kitabında iddia ettiği gibi, cinsiyetçi dil durdurulamaz, kontrol edilemez, değiştirilemez; ne kadar uğraşırsanız uğraşın o yine başka bir yerde başka bir şekilde ortaya çıkacaktır (p.38). Bunun nedeni kültürle dilin sürekli karşılıklı iletişim içinde olmasıdır. Ataerkil toplumlarda kadının ikincil rollerinden kaynaklanan dildeki ifadeler, yıllar içinde tekrarlanarak kadının kimliğini pekiştirmektedir. Bu nedenle toplumu kadın hakkındaki önyargılardan arındırmak ve gerçek anlamda kadın erkek eşitliğini sağlamak istiyorsak buna öncelikle konuştuğumuz dilden başlamalıyız.

\section{Kaynakça}

AKSAN, D. (1998). Her Yönüyle Dil. Ankara: Türk Dil Kurumu Yayınları.

BEATTIE, G. W. (1981). Interruption in conversational interaction and its relation to the sex status of the interactants. Linguistics 19,5-35.

BUTLER, J. (1993). Bodies That Matter: On the Discursive Limits of "Sex". New York: Routledge.

CAMERON, D.(ed) (1990). The Feminist Critique of Language: A Reader. New York: Routledge

CAMERON, D. (1995). Rethinking Language and Gender Studies: Feminism into the 1990s, S. Mills8ed) Language and Gender: Interdisciplinary Perspectives. London: Longman

COATES, J. (1986). Women, Men and Language: A Sociolinguistic Account of Gender Differences in Language. London: Longman.

COATES, J. \& CAMERON, D. (ed) (1988). Women in their speech communities: New Perspectives on Language and Sex. New York: Longman.

ECKERT, P. \& McConnell- Ginet, S. (1992). "Think Practically and Look Locally: Language and Gender as Community-Based Practice", Annual Review of Anthropology. Vol.21, s.461-490.

FREEMAN, R.D. \& McElhinny, B. (1996). Language and Gender, S. MaKay \& N. Hornberger (ed), Sociolinguistics and Language Teaching. Cambridge: Cambridge University Press

FISHMAN, P. M.(1978). Interaction: The Work Women Do, Social Problems. 25, 397-406.

GRAY, J. (2012). Men Are from Mars, Women Are from Venus: The Classic Guide to Understanding the Opposite Sex. London: Harper Collins Publishing. 
GOODWIN, M. (1998). Cooperation and Competition Across girls' Play Activities, J. Coates (ed) Language and Gender: A Reader. s.121-146, Oxford: Blackwell.

GREIF, E. (1980). Sex differences in parent-child conversation, Women's Studies International Quarterly, Vol.3, 253-258.

JESPERSEN, O.(1992). Language: its Nature, Development and Origin. New York: Henry Holt \& Co.

LAKOFF, R. (1973). Language and Woman's Place, Language in Society, Vol. 2, No 1, 45-80

LAKOFF, R.(1975). Language and Woman's Place. New York: Harper and Row

O'BARR, W.\& ATKINS, B. (1980), "Women's Language" or "Powerless Language", S. McConnell-Ginet, R. Borker, N. Furman(ed) Women and Language in Literature and Society. New York: Praeger

SPENDER, D.(1980). Man Made Language. London: Routledge and Kegan Paul.

SUNDERLAND, J. (1996). Gender representation in EFL materials: suggestions for teacher development, Teacher Development 32: 21-23

SUNDERLAND, J.(2004). Gendered Discourse. New york: Palgrave Macmillan.

SUNDERLAND, J. (2006). Language and Gender. London: Routledge

TANNEN, D. (1991). You Just Don't Understand. New York: Ballantine Books, YURTBAŞI, M. (2012),. A Dictionary of Turkish Proverbs. İstanbul: Excellence Publishing.

ZIMMERMAN, D. H. , WEST, C. (1975). Sex Roles, Interruptions and Silences in Conversation, B. Thorne\& N. Henley (ed) Language and Sex Difference and Dominance. Rowley MA: Newbury House. 